\title{
Usos de anticuerpos monoclonales en medicina
}

\author{
Monoclonal antibodies in medicine \\ Juan Fernando Flores Ramírez ${ }^{1}$, Humberto García Bernal ${ }^{2}$, Ernesto Ulises Morales León ${ }^{3}$, \\ Cristian Ulises Islas Martínez $z^{4}$
}

\begin{abstract}
:
Monoclonal antibodies are specialized glycoproteins, resulting from the combination of cell mother and clone ofb-lymphocyte (hybridoma) Antibody monoclonal $(\mathrm{mAB})$ have acquired greater importance in the treatment of various diseases, as well as in clinical diagnosis because of its high specificity and uniformity. The use of mAB currently varies from the treatment for cancer and autoimmune diseases to its use in ophthalmology or asthma.
\end{abstract}

Keywords:

Monoclonal antibodies, Glycoproteins, Cell mother, Hybridoma, Specificity

\section{Resumen:}

Los anticuerpos monoclonales son glucoproteínas especializadas que resultan de la combinación de una célula madre y un clon de linfocito B (hibridoma). Los anticuerpos monoclonales (mAB) han adquirido mayor importancia en el tratamiento de diversas enfermedades, así como en el diagnóstico clínico debido a su alta especificidad y homogeneidad. El uso de mAB en la actualidad varía desde el tratamiento contra el cáncer y enfermedades autoinmunes hasta su uso en oftalmología o en el asma.

\section{Palabras Clave:}

Anticuerpos monoclonales, glucoproteínas, célula madre, hibridoma, especificidad.

\section{Desarrollo}

Lorem El desarrollo y mutación de agentes patógenos en el organismo ha llevado a la medicina a la constante investigación de nuevas formas de diagnóstico y tratamiento para dichas enfermedades, esto con el objetivo de fortalecer los servicios de salud. Bajo este objetivo el desarrollo de anticuerpos monoclonales surge como respuesta para el tratamiento de pacientes con diagnósticos poco favorables.

\subsection{Anticuerpos monoclonales}

Los anticuerpos monoclonales son el resultado de la fusión en cultivo de un clon de linfocito B y una célula madre totipotencial. Con el fin de obtener las características principales de cada célula.

Según la revista médica de Chile en 2003 los anticuerpos son:

-Proteínas que envuelven una estructura bioquímica compleja demarcada por la unión de cuatro cadenas proteicas: dos pesadas $(\mathrm{CH})$, y dos ligeras $(\mathrm{CL})$, unidas mediante puentes disulfuro. Funcionalmente, los anticuerpos se dividen en una fracción que involucra el reconocimiento antigénico, denominada $\mathrm{Fab}$, y una fracción cristalizable $(F c)$ que media funciones efectoras como la citotoxicidad celular que depende del anticuerpo (antibody dependant cellular cytotoxicity, ADCC) y la citotoxicidad que depende del complemento (CD) $(2,4)$. - Los anticuerpos monoclonales (mAB) por definición corresponde al resultado de una célula madre y un clon de linfocito B (hibridoma). La técnica que da como resultado la hibridoma fue descubierta por Niels K. Jerne, Georges Köhler y Cesar Milstein en 1975.

\subsection{Finalidad de los anticuerpos monoclonales}

${ }^{1}$ Lic. Médico Cirujano, Universidad Autónoma de Estado de Hidalgo, Escuela superior de Tepeji del Rio, Av. Del Maestro No. 41 Colonia Noxtongo 2a Sección, Tepeji del Rio, Hidalgo, México. Email: juanfer.fer24@gmail.com.

2 beto25031997@gmail.com, 3 ulises.ml179@gmail.com, 4 cristianulisesm@ gmail.com 
Según la revista médica de Chile en 2003 la finalidad de los anticuerpos monoclonales es:

- Fusionar un linfocito B con una célula mieloma es conservar la propiedad del linfocito B y la capacidad de la célula de mieloma de replicarse en un cultivo. Los anticuerpos deseados para la producción de mAB se consiguen mediante la inmunización de células de mieloma de un ratón y el antígeno de interés, se realiza una extracción y posteriormente disociación del bazo en el medio de cultivo.

\subsection{Los anticuerpos monoclonales en la clínica}

En el caso de la clínica los anticuerpos monoclonales son de gran relevancia. Un ejemplo de ello en caso de carcinomas los anticuerpos identifican las células mutadas para su correcta eliminación; en el caso del tratamiento de carcinomas se utiliza en quimioterapias para disminuir el efecto secundario. Los anticuerpos en general participan en las reacciones de antígeno anticuerpo. Detectar y cuantificar niveles de expresión de genes. Determinar la localización de la expresión de genes a nivel celular, subcelular y en los tejidos. Identificar las interacciones moleculares con los productos de genes, por ejemplo, la inmuno-precipitación. Identificación de marcadores fenotípicos únicos de un tipo celular particular; ésta es la base de la moderna clasificación de linfocitos y fagocitos monucleares.

\subsection{Inmunodiagnóstico}

En el diagnóstico de muchas enfermedades infecciosas y sistémicas al permitir la detección de antígenos y anticuerpos específicos en la circulación o tejidos usando anticuerpos monoclonales en inmunoensayos, y como marcadores específicos para el diagnóstico por imágenes. Diagnóstico y tratamiento de tumores específicos: los anticuerpos monoclonales se usan en la detección de tumores mediante técnicas inmunológicas de diagnóstico y para la inmunoterapia de tumores in vivo. Análisis funcionales de moléculas de la superficie celular o de proteínas secretorias.

Según Machado, N.P en 2006 los anticuerpos monoclonales son:

- Herramientas esenciales en el ámbito clínico y biotecnológico además han probado ser útiles en el diagnóstico y tratamiento de enfermedades infecciosas, inmunológicas y neoplásicas.

- La inclusión de los anticuerpos monoclonales en la clínica permite agregar especificidad y reproductividad en las reacciones de antígeno-anticuerpo lo que permite un mejor estudio de estas mismas reacciones. Debido a que los $\mathrm{mAB}$ son producidos por células de mieloma (antígenos de ratón) pueden producir efectos secundarios [1].

Como menciona machado en su trabajo debido a que los anticuerpos monoclonales son producidos por inmunoglobulina de ratón se presentan reacciones adversas; Sin embargo, en la actualidad se ha podido realizar anticuerpos humanizados.

Para la creación de anticuerpos monoclonales humanizados se necesita que las secuencias de DNA sean modificadas con el fin de aumentar la similitud con los distintos anticuerpos producidos de manera natural en el organismo.

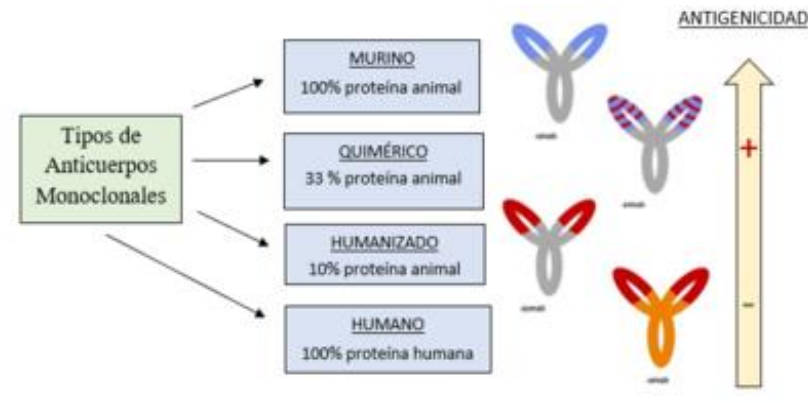

Figure 1. Tipos de anticuerpos monoclonales

\subsection{Desarrollo de anticuerpos monoclonales en la historia}

Los primeros anticuerpos fueron creados a partir de relaciones con antígenos de ratones con tecnología de recombinación. Las secuencias de DNA, las cuáles serán posteriormente insertados en células de mieloma, son anticuerpos que tendrán una unión especifica de antígeno generado a base de inmunoglobulina de ratón; sin embargo, genera efectos adversos.

Según Machado, N.P en 2006:

-En 1985 se crearon los primeros anticuerpos quiméricos humanos a partir de ratones, con la tecnología del ADN recombinante, en la cual los genes que codifican la región variable de las lg de ratón se unen con genes que codifican la región constante humana para, luego, ser insertados en células de mieloma, donde producirán nuevas moléculas de anticuerpo que tendrán una parte humana pero que tienen la unión específica del antígeno (Fab) generada en ratones. Una de las limitaciones presentadas con la quimerización de anticuerpos monoclonales de ratón es la baja frecuencia de transformantes que produzcan el anticuerpo quimérico. Aunque los anticuerpos monoclonales quiméricos son menos inmunogénicos que los anticuerpos monoclonales de ratón se han observado respuestas importantes de tipo anticuerpo-antiquiméricos en el $40 \%$ de los productos que se han usado en humanos. 
- La construcción de anticuerpos monoclonales humanizados se da gracias a la ingeniería de proteínas. En este proceso se transfieren los CDR provenientes de las Ig de ratón a estructuras de las regiones variables de cadenas pesadas o ligeras de una lg proveniente de una especie diferente, en este caso, la humana [2].

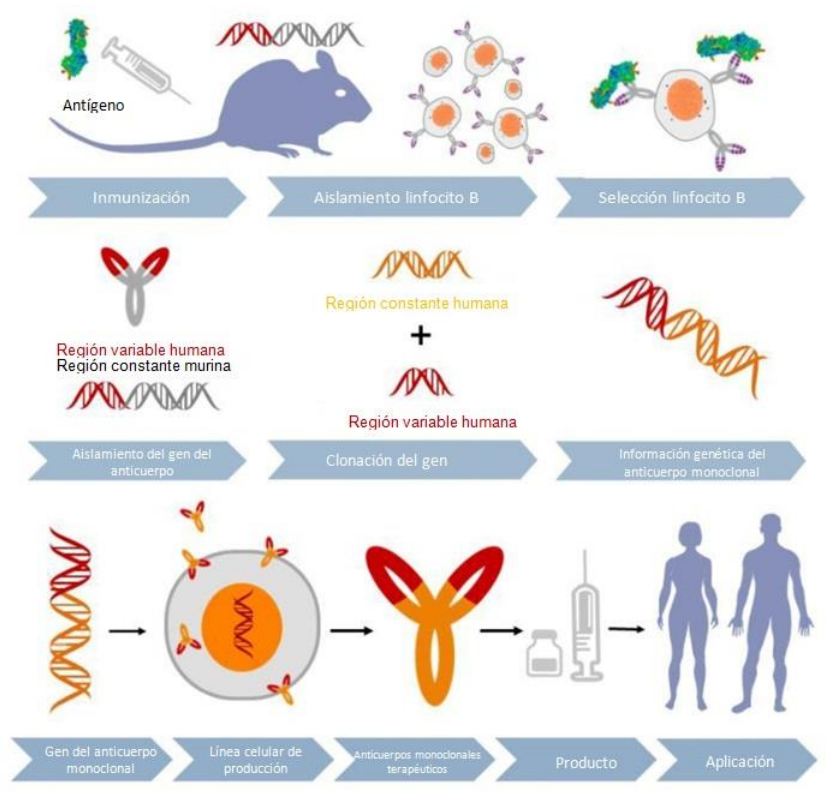

Figure 2. Desarrollo de anticuerpos

\subsection{Mecanismos de acción de los anticuerpos monoclonales}

Dada su alta especificidad y reproductividad los anticuerpos monoclonales serán inhibidores de receptores Fat en enfermedades autoinmunes. En pacientes inmunocomprometidos ayuda a el bloqueo de agentes con marcadores no identificados por células linfoides. Sin embargo, los mecanismos de acción de los anticuerpos monoclonales varían dependiendo la propiedad de la inmunoglobulina que se extraiga o secuencia de DNA que se potencialice en la célula de mieloma totipotencial [3].

Basado en el trabajo de Osorio LM, Ordoñez C, García $\mathrm{CA}$, Jondal M.:

Los mecanismos de acción de los anticuerpos monoclonales funcionan como bloqueo de una respuesta, previniendo el acceso de mediadores solubles; como marcador de células tumorales por unión de antígenos específicos, permitiendo la opsonización y posterior destrucción de la célula, por lisis mediada por el mAb y dependiente del sistema del complemento;

desencadenamiento de señales intracelulares, inductoras de apoptosis a través de anticuerpos antiidiotipo; transporte de sustancias radiactivas o citostáticas; potenciación de la respuesta inmune de células $T$, dirigida contra antígenos tumorales desconocidos. Entre estos se encuentran los anti-CD40, anti-CD137, anti-CTLA-4, antiBAT2 [4].

Los anticuerpos, también denominados inmunoglobulinas (lg), son glucoproteínas especializadas que hacen parte de la inmunidad humoral; son producidas por las células del sistema inmune llamadas células $B$, que tienen la capacidad de reconocer otras moléculas específicas llamadas antígenos. La respuesta inmunológica específica se desarrolla cuando un organismo ha sido expuesto a uno o varios antígenos, originando una respuesta policlonal, es decir, la producción de anticuerpos contra un rango amplio de estructuras presentes en los antígenos. Por el contrario, la respuesta monoclonal se da por la selección de un solo clon activado de células $B$ que produce un anticuerpo para un determinante antigénico único [5].

\section{Resultados}

\begin{tabular}{|c|c|c|c|c|}
\hline Anticuerpo & $\begin{array}{l}\text { Nombre } \\
\text { comercial }\end{array}$ & $\begin{array}{c}\text { Fecha de } \\
\text { aprobaci } \\
\text { ón }\end{array}$ & Blanco & $\begin{array}{c}\text { Tratamiento } \\
\text { indicado }\end{array}$ \\
\hline $\begin{array}{l}\text { Alemtuzum } \\
\text { ab } \\
\text { Quimérico }\end{array}$ & Campath & 2001 & CD52 & $\begin{array}{c}\text { Leucemia } \\
\text { linfocítica } \\
\text { crónica } \\
\end{array}$ \\
\hline $\begin{array}{c}\text { Bevacizuma } \\
\text { b } \\
\text { Humanizad } \\
\text { o }\end{array}$ & Avastin & 2004 & $\begin{array}{c}\text { Factor de } \\
\text { crecimien } \\
\text { to } \\
\text { vascular } \\
\text { endotelial } \\
\text { (VEGF) }\end{array}$ & $\begin{array}{c}\text { Cáncer } \\
\text { colorectal } \\
\text { relacionado } \\
\text { con } \\
\text { degeneración } \\
\text { macular senil } \\
\end{array}$ \\
\hline $\begin{array}{l}\text { Cetuximab } \\
\text { Quimérico }\end{array}$ & Erbitux & 2004 & $\begin{array}{c}\text { Receptor } \\
\text { del factor } \\
\text { de } \\
\text { crecimien } \\
\text { to } \\
\text { epidermal }\end{array}$ & $\begin{array}{c}\text { Cáncer } \\
\text { colorectal, } \\
\text { cáncer de } \\
\text { cuello y } \\
\text { cabeza }\end{array}$ \\
\hline $\begin{array}{c}\text { Gemtuzuma } \\
\text { b } \\
\text { Humanizad } \\
\text { o }\end{array}$ & Mylotarg & 2000 & CD33 & $\begin{array}{c}\text { Leucemia } \\
\text { aguda } \\
\text { mielogenética } \\
\text { (con } \\
\text { caliqueamicin } \\
\text { a) }\end{array}$ \\
\hline $\begin{array}{c}\text { Ibritumoma } \\
\text { b tiuxetan } \\
\text { Murino }\end{array}$ & Zevalin & 2002 & CD20 & $\begin{array}{c}\text { Linfoma No } \\
\text { Hodgkin (con } \\
\text { Ytrio-90 o } \\
\text { Indio 111) } \\
\end{array}$ \\
\hline $\begin{array}{c}\text { Patitumuma } \\
\text { b Humano }\end{array}$ & Vectibix & 2006 & $\begin{array}{l}\text { Receptor } \\
\text { del factor } \\
\text { de } \\
\text { crecimien } \\
\text { to } \\
\text { epidermal }\end{array}$ & $\begin{array}{l}\text { Cáncer } \\
\text { colorectal }\end{array}$ \\
\hline $\begin{array}{l}\text { Rituximab } \\
\text { Quimérico }\end{array}$ & $\begin{array}{l}\text { Vectibixritux } \\
\text { an, Mabthera }\end{array}$ & 1997 & CD20 & $\begin{array}{c}\text { Linfoma No } \\
\text { Hodgkin }\end{array}$ \\
\hline $\begin{array}{l}\text { Tositumom } \\
\text { ab Murino }\end{array}$ & Bexxar & 2003 & CD20 & $\begin{array}{c}\text { Linfoma No } \\
\text { Hodgkin }\end{array}$ \\
\hline $\begin{array}{c}\text { Trastuzuma } \\
\text { b } \\
\text { Humanizad } \\
\text { o }\end{array}$ & Herceptin & 1998 & ErbB2 & $\begin{array}{l}\text { Cáncer de } \\
\text { mama }\end{array}$ \\
\hline
\end{tabular}

\section{Conclusión}


Los anticuerpos monoclonales debido a su especificidad han resultado un gran avance; sin embargo, la investigación debe basarse en los anticuerpos monoclonales humanizados para suprimir la respuesta adversa.

\section{Agradecimientos}

Le agradecemos a Dios y a la vida por colocarnos en esta hermosa carrera que es medicina, además agradecemos al Dr. Karthik por motivarnos día con día a motivarnos por entrar al ámbito de la investigación 1.

\section{Referencias}

[1]Machado, N. P. (10 de 3 de 2006). Anticuerpos monoclonales: desarrollo físico y perspectivas terapéuticas. Obtenido de www.scielo.org.co/pdf/inf/v10n3/v10n3a06.pdf

[2]Machado, N. P. (2006). Anticuerpos monoclonares: desarrollo físico y perspectivas terapéuticas. Obtenido de www.revistainfectio.org/index.php/infectio/article/view/174/150

[3]Revista Médica de Chile. (diciembre de 2003). Obtenido de https://scielo.conicyt.cl/scielo.php?pid=S0034-

98872003001200013\&script=sci_arttext\&tIng=pt

[4]Nelson AL, Dhimolea E., Reichert JM. Development trends for human monoclonal antibody therapeutics. Nat Rev Drug Discov. 2010

[5]Trail PA, Bianchi AB. Monoclonal antibody drug conjugates in the treatment of cancer. Curr Opin Immunol 1999 